\title{
PENGARUH LATIHAN PLYOMETRIC BOX JUMP DAN PLYOMETRIC STANDING JUMP TERHADAP KEMAMPUAN VERTICAL JUMP PADA ATLET KLUB BOLA VOLI
}

\author{
Bayu Adhitya Bagaskara ${ }^{1}$, Suharjana ${ }^{1}$ \\ ${ }^{1}$ Fakultas Ilmu Keolahragaan, Universitas Negeri Yogyakarta, Colombo No. 1, Karangmalang Depok, Sleman, \\ Yogyakarta, Indonesia \\ bayu.adhitya@student.uny.ac.id, suharjana@uny.ac.id
}

\begin{abstract}
Abstrak
Penelitian ini bertujuan untuk mengetahui: 1) adakah pengaruh latihan Box jump terhadap vertical jump atlet putra Ganevo usia 14-17 tahun, 2) adakah pengaruh latihan standing jump terhadap vertical jump atlet putra Ganevo usia 14-17 tahun, 3) jenis latihan yang lebih efektif terhadap vertical jump atlet putra Ganevo usia 14-17 tahun. Penelitian ini adalah experiment dengan desain penelitian yang digunakan adalah "two groups pretest-posttest design". Instrumen dalam penelitian ini tes vertical jump dengan reliabilitas 0,99 dan validitas 0,989. Subjek dalam penelitian adalah Atlet Klub Bola Voli Ganevo Usia 14 - 17 Tahun yang berjumlah 24 Atlet. Teknik analisis data menggunakan uji t dengan taraf signifikansi $5 \%$. Hasil penelitian menyimpulkan: (1) ada pengaruh latihan plyometric box jump terhadap vertical jump atlet bola voli putra Ganevo Usia 14-17 tahun, dengan $t$ hitung $(8,660)>t$ table $(2,201)$, dan nilai Signifikansi $(0,000)<$ dari $(0,05),(2)$ ada pengaruh latihan plyometric standing jump terhadap vertical jump atlet bola voli putra Ganevo Usia 14-17 tahun, dengan $t$ hitung $(3,522)>t$ table $(2,201)$, dan nilai Signifikansi $(0,005)<$ dari $(0,05)$, (3) latihan plyometric standing jump lebih baik untuk meningkatkan vertical jump atlet bola voli Ganevo putra Usia 14-17 tahun, dengan $t$ hitung $(2,133)>t$ table $(1,720)$, dan nilai Signifikansi $(0,026)<$ dari $(0,05)$. Selisih posstest sebesar $1,75 \mathrm{~cm}$.
\end{abstract}

Kata kunci: Plyometric box jump, plyometric standing jump, kemampuan Vertical Jump

\section{EFFECT OF PLYOMETRIC BOX JUMP AND PLYOMETRIC STANDING JUMP TOWARD VERTICAL JUMP ABILITY IN VOLLEY BALL CLUB ATHLETES}

\begin{abstract}
This study aims to determine: 1) is there any influence of Box jump training on vertical jumps of Ganevo male athletes aged 14-17 years, 2) is there any influence of standing jump exercises on vertical jumps of Ganevo male athletes aged 14-17 years, 3) is there any types of exercises give effective effect toward vertical jump of male athlete Ganevo aged 14-17 years. This research is an experiment study using two groups pretest-posttest design. The instrument in this study was a vertical jump test with a reliability of 0.99 and a validity of 0.989. Subjects in this study were Ganevo Volleyball Club Athletes Aged 14-17 Years, 24 Athletes in total as subjects. Data analysis techniques used the t test with a significance level of 5\%.The results of the study concluded: (1) there was an effect of plyometric box jump training on the vertical jump of male volleyball athlete Ganevo Age 14-17 years, with t count $(8,660)>t$ table $(2,201)$, and the Significance value $(0,000)<$ of $(0,05)$, (2) there is the influence of plyometric standing jump training on the vertical jump of male volleyball athlete Ganevo Age 14-17 years, with t arithmetic $(3,522)>$ t table $(2,201)$, and the Significance value $(0.005)<$ of $(0,05),(3)$ plyometric standing jump training is better to increase vertical jump for volleyball athletes of Ganevo men aged 14-17 years, with t arithmetic $(2,133)>t$ table $(1,720)$, and significance value $(0.026)<o f(0.05)$. Post-test difference of $1.75 \mathrm{~cm}$.
\end{abstract}

Kata kunci: Plyometric box jump, plyometric standing jump, Vertical Jump ability 


\section{PENDAHULUAN}

Bola voli merupakan salah satu cabang olahraga yang memasyarakat di Indonesia. Dalam permainan bola voli, memiliki berbagai tujuan yakni bisa sebagai olahraga pendidikan, olahraga rekreasi dan olahraga untuk meraih prestasi. Ahmadi (2007: 19) berpendapat bahwa bola voli merupakan suatu permainan yang kompleks yang tidak mudah dilakukan oleh setiap orang. Diperlukan teknik-teknik dasar dan teknik-teknik lanjutan untuk dapat bermain bola voli secara efektif.

Daerah Istimewa Yogyakarta khususnya di klub bola voli Ganevo, pembinaan sudah dilakukan secara bertahap mulai dari tahap multilateral sampai tahap spesifikasi. Menurut Reza (2017: 2) terdapat beberapa faktor yang menunjang pningkatan prestasi olahraga bola voli, diantaranya: (1) Dukungan keluarga, (2) Pendanaan, (3) Motivasi atlet, (4) Kualitas Pelatih, (5) pemilihan Bakat, (6) Manajemen, (7) Program Latihan, (8) waktu Latihan, dan (9) evaluasi. Klub bola voli Ganevo memiliki jadwal latihan rutin 4 kali dalam seminggu, yaitu: senin, rabu, jum "eat dan minggu. Hari senin, rabu dan jum "eat latihan dimulai dari pukul 15:30-17:30 WIB, sedangkan pada hari minggu latihan dimulai dari pukul 07:00-10:00 WIB. Dalam permainan bola voli salah satu hal yang berperan adalah lompatan. Banyak orang yang ingin melatih lompatan agar memiliki vertical jump yang tinggi agar mempermudah untuk menjangkau bola dalam permainan bola voli.

Kemampuan melompat sangatlah penting untuk kesuksesan dalam bola voli, yang memungkinkan terjadinya keunggulan kompetitif dalam serangan (mendapatkan ketinggian yang besar untuk menyerang) dan juga dalam pertahanan melakukan blocking, Newton(dalam Reza 2017: 3). Dalam melakukan vertical jump power otot tungkai sangat dibutuhkan sehingga perlu diupayakan peningkatan latihan terutama latihan power tungkai. Power otot tungkai yang baik akan menghasilkan loncatan yang baik pula sehingga akan lebih mudah untuk melakukan smash maupun block (Indrayana, 2018). Dalam meningkatkan latihan vertical jump yang harus diperhatikan adalah latihan pegembangan daya ledak (explosive power) dengan demikian, hasil vertical jump yang baik selain didapatkan dari penguasaan teknik yang baik juga dipengaruhi oleh kondisi fisik yang baik pula, salah satunya daya ledak (explosive power).

Menurut Suharjana (2013: 38) Latihan adalah memberikan penekanan fisik yang teratur, sistematis, dan berkesinambungan sedemikian rupa sehingga dapat meningkatkan kemampuan dalam melakukan kerja dan meningkatkan kebugaran jasmani atau kemampuan fisik. Dengan latihan yang terstruktur akan meningkatkan kemampuan fisik pemain. Terdapat tiga sistem dalam penyelenggaraan suatu latihan, yaitu kardiovaskuler, muskuloskeletal, dan neuromuskuler.

Pada musculoskeletal jenis latihan yang dilakukan oleh masyarakat pada umumnya seperti jenis latihan konvensional dan latihan pembebanan. Jenis latihan konvensional ini menekankan gerakan melompat untuk meningkatkan daya ledak. Pada musculoskeletal jenis latihan yang dilakukan oleh masyarakat pada umumnya seperti jenis latihan konvensional dan latihan pembebanan. Jenis latihan konvensional ini menekankan gerakan melompat untuk meningkatkan daya ledak otot tersebut, latihan yang berbentuk gerakan melakukan lompatan, daya ledak otot dilatih dengan gerakan berulang seperti melompat. Sehingga dengan intensitas maksimum dan dikontrol dengan baik akan dapat meningkatkan tinggi lompatan. Sedangkan pada latihan isometric melatih kekuatan otot dan stabilisasi sendi tersebut secara perlahan sehingga dengan intensitas yang maksimum dan dikontrol juga akan sangat baik dalam menunjang peningkatan vertical jump. Untuk melatih vertical jump secara efisien salah satunya melalui latihan plyometric. Karena dalam latihan plyometric adalah bentuk latihan yang gerakanya eksplosif dengan selain efisien juga akan tercakup unsur-unsur yang terlatih, seperti kekuatan otot, ketahanan otot, kelentukan, kelincahan 


\section{METODE}

Penelitian ini adalah penelitian eksperimen, artinya penelitian yang bertujuan mencari hubungan kausalita atau sebab akibat. Penelitian eksperimen diakui sebagai penelitian yang paling ilmiah dari seluruh tipe penelitian karena peneliti dapat memanipulasi perlakuan yang menyebabkan terjadinya sesuatu. Penelitian eksperimen adalah metode penelitian yang digunakan untuk mencari pengaruh perlakuan tertentu terhadap yang lain dalam kondisi yang terkendalikan (Sugiyono, 2014: 72).

Desain penelitian yang digunakan dalam penelitian ini adalah "two groups pretestposttest design", yaitu desain penelitian yang terdapat pretest sebelum diberi perlakuan dan posttest setelah diberi perlakuan. Dengan demikian dapat diketahui lebih akurat, karena dapat membandingkan dengan diadakan sebelum diberi perlakuan (Sugiyono, 2014: 64). Penelitian ini akan membandingkan hasil pretest dan posttest vertical jump. Sampel dibagi menjadi dua kelompok, dalam waktu bersamaan kelompok satu melakukan latihan plyometric box jump, kelompok dua melakukan latihan plyometric standing jump.

Populasi dalam penelitian ini adalah seluruh Atlet Klub bola voli Ganevo usia 14-17 tahun dengan jumlah 47 Atlet. Usia 14 - 17 tahun dipilih sebagai subjek penelitiani karena pada usia tersebut masa perkembangan dan prestasi yang cukup baik karena anak sudah mampu memproses informasi visual secara cepat dan tepat dalam memaksimalkan latihan serta pola pikir anak sudah berkembang sehingga lebih mudah untuk mengarahkan.

Sampel yang digunakan dalam penelitian ini diambil secara purposive sampling dengan kriteria sebagai berikut yaitu: (a) Atlet Klub bola voli Ganevo usia 14-17 tahun yang masih aktif latihan. (b) keaktifan dalam mengikuti latihan 3 kali seminggu. (c) sanggup mengikuti seluruh program latihan yang telah disusun selama 18 kali pertemuan. (d) tidak melakukan tuntutan/ menuntut apabila terjadi sesuatu dalam diri sampel yang diakibatkan oleh program latihan yang dijalani selama proses latihan. Dengan beberapa kriteria diatas maka jumlah sampel adalam penelitian ini adalah sebanyak 24 Atlet.

\section{HASIL DAN PEMBAHASAN}

Pada penelitian ini bermaksud untuk mengetahui pengaruh latihan plyometric box jump dan plyometric standing jump terhadap kemampuan vertical jump pada atlet klub bola voli putra ganevo Usia 14-17 Tahun. Hasil penelitian diperoleh berdasarkan pada hasil pretest dan postest data kemampuan vertical jump pada atlet klub bola voli putra Ganevo Usia 14-17 Tahun dari masing-masing data tersebut diuraikan sebagai berikut:

\section{Data Kemampuan Vertical Jump dengan Latihan Plyometric Box Jump}

Hasil statistik data kemampuan vertical jump dengan latihan plyometric box jump pada atlet klub bola voli Putra Ganevo Usia 14-17 Tahun dalam penelitian ini di ukur dengan tes vertical jump. Hasil penelitian data kemampuan vertical jump diperoleh sebagai berikut:

Tabel 1. Statistik Data Kemampuan Vertical Jump Dengan Latihan Plyometric Box Jump

\begin{tabular}{|l|l|l|}
\hline Keterangan & Pretest & Posttest \\
\hline Mean & 56,5 & 59 \\
\hline Median & 57,5 & 59 \\
\hline Mode & 53 & 48 \\
\hline Std. Deviation & 7,19 & 6,86 \\
\hline Minimum & 45 & 48 \\
\hline Maximum & 69 & 71 \\
\hline
\end{tabular}


MEDIKORA, Vol. XVIII No. 2 Oktober 2019 - 67

Bayu Adhitya Bagaskara, Suharjana

Tabel 2. Deskripsi Kemampuan Vertical Jump dengan Latihan Plyometric Box Jump

\begin{tabular}{|l|l|l|l|l|}
\hline \multirow{2}{*}{$\begin{array}{c}\text { Putra Umur } \\
\text { 14-17 Tahun }\end{array}$} & \multicolumn{2}{|c|}{ Pretest } & \multicolumn{2}{c|}{ Posttest } \\
\cline { 2 - 5 } & F & \multicolumn{1}{c|}{$\%$} & \multicolumn{1}{c|}{ F } & \% \\
\hline $66-72$ & 1 & 8,33 & 2 & 16,67 \\
\hline $59-65$ & 4 & 33,33 & 4 & 33,33 \\
\hline $52-58$ & 4 & 33,33 & 4 & 33,33 \\
\hline $45-51$ & 3 & 25 & 2 & 16,67 \\
\hline Jumlah & 12 & 100 & 12 & 100 \\
\hline
\end{tabular}

\section{Data Kemampuan Vertical Jump dengan Latihan Plyometric Standing Jump}

Hasil statistik data penelitian Kemampuan Vertical Jump dengan Latihan Plyometric Standing Jump diperoleh sebagai berikut:

Tabel 3. Kemampuan Vertical Jump dengan Latihan Plyometric Standing Jump

\begin{tabular}{|l|l|l|}
\hline Keterangan & Pretest & Posttest \\
\hline Mean & 48,92 & 53,17 \\
\hline Median & 48,5 & 53 \\
\hline Mode & 45 & 40 \\
\hline Std. Deviation & 9,79 & 8,54 \\
\hline Minimum & 28 & 40 \\
\hline Maximum & 65 & 66 \\
\hline
\end{tabular}

Tabel 4. Deskripsi Data Kemampuan Vertical Jump dengan Latihan Plyometric Standing Jump

\begin{tabular}{|c|l|l|l|l|}
\hline \multirow{2}{*}{$\begin{array}{c}\text { Putra Umur } \\
\text { 14-17 Tahun }\end{array}$} & \multicolumn{2}{|c|}{ Pretest } & \multicolumn{2}{c|}{ Posttest } \\
\cline { 2 - 5 } & F & \% & F & \multicolumn{1}{c|}{} \\
\hline $58-67$ & 3 & 25 & 4 & 33,33 \\
\hline $48-57$ & 3 & 25 & 5 & 41,67 \\
\hline $38-47$ & 5 & 41,67 & 3 & 25 \\
\hline $28-37$ & 1 & 8,33 & 0 & 0 \\
\hline Jumlah & 12 & 100 & 12 & 100 \\
\hline
\end{tabular}

Persentase Peningkatan Kemampuan Vertical Jump dengan Latihan Plyometric Box Jump dan Plyometric Standing Jump

Untuk mengetahui besarnya peningkatan kemampuan vertical jump dengan latihan plyometric box jump dan plyometric standing jump dalam penelitian ini menggunakan rumus peningkatan persentase

Tabel 5. Persentase Peningkatan Kemampuan Vertical Jump dengan Latihan Plyometric Box Jump Dan Plyometric Standing Jump

\begin{tabular}{|l|l|l|l|}
\hline Variabel & Pretest & Posttest & $\begin{array}{l}\text { Persetase } \\
\text { peningkatan }\end{array}$ \\
\hline $\begin{array}{l}\text { Kemampuan Vertical Jump dengan Latihan } \\
\text { Plyometric Box Jump }\end{array}$ & 56,5 & 59 & 4,44 \\
\hline $\begin{array}{l}\text { Kemampuan Vertical Jump dengan Latihan } \\
\text { Plyometric Standing Jump }\end{array}$ & 48,92 & 53,17 & 8,6 \\
\hline
\end{tabular}




\section{Hasil Analisis Data Penelitian \\ Uji Normalitas}

Hasil uji normalitas dapat dilihat pada tabel di bawah ini:

Tabel 6. Hasil Uji Normalitas

\begin{tabular}{|l|l|l|l|l|l|}
\hline \multicolumn{2}{|c|}{ Variabel } & Z & P & Sig 5 \% & Keterangan \\
\hline $\begin{array}{l}\text { Kemampuan Vertical } \\
\text { Jump dengan Latihan } \\
\text { Plyometric Box Jump }\end{array}$ & Pretest & 0,385 & 0,998 & 0,05 & Normal \\
\cline { 2 - 6 } & Posttest & 0,326 & 0,990 & 0,05 & Normal \\
\hline $\begin{array}{l}\text { Kemampuan Vertical } \\
\text { Jump dengan Latihan } \\
\text { Plyometric Standing } \\
\text { Jump }\end{array}$ & Pretest & 0,616 & 0,842 & 0,05 & Normal \\
\cline { 2 - 6 } & Posttest & 0,310 & 0,996 & 0,05 & Normal \\
\hline
\end{tabular}

\section{Uji Homogenitas}

Berdasarkan hasil uji homogenitas di atas kemampuan vertical jump dengan latihan plyometric box jump dan plyometric standing jump diperoleh nilai $\mathrm{F}$ hitung $<\mathrm{F}$ tabel $(4,28)$, dengan hasil yang diperoleh tersebut dapat disimpulkan bahwa varians bersifat homogen.

Tabel 7. Hasil Uji Homogenitas

\begin{tabular}{|c|c|c|c|c|c|}
\hline Test & df & F tabel & F hit & $P$ & Keterangan \\
\hline $\begin{array}{c}\text { Kemampuan Vertical Jump } \\
\text { dengan Latihan Plyometric } \\
\text { Box Jump }\end{array}$ & $1: 22$ & 4,28 & 0,066 & 0,800 & Homogen \\
\hline $\begin{array}{c}\text { Kemampuan Vertical Jump } \\
\text { dengan Plyometric Standing } \\
\text { Jump }\end{array}$ & $1: 22$ & 4,28 & 0,034 & 0,854 & Homogen \\
\hline
\end{tabular}

\section{Uji Hipotesis}

\section{Perbandingan Pretest dan Posttest Kemampuan Vertical Jump dengan Latihan}

\section{Plyometric Box Jump}

Dari hasil uji-t dapat dilihat bahwa t hitung $(8,660)>\mathrm{t}$ tabel $(2,201)$, dan nilai $p(0,000)$ $<$ dari $(0,05)$, maka hasil tersebut menunjukkan bahwa terdapat perbedaan yang signifikan, memberikan pengaruh signifikan terhadap vertical jump atlet bola voli putra Ganevo usia 1417 tahun. Dari data pre-test memiliki rerata 56.5, selanjutnya pada posttest rerata mencapai 59.0. besarnya perubahan tersebut dapat dilihat dari perbedaan rata-rata yaitu sebesar $2.5 \mathrm{~cm}$.

Tabel 8. Uji t hasil pre-test dan posttest vertical jump latihan box jump

\begin{tabular}{|c|c|c|c|c|c|c|c|}
\hline \multirow{2}{*}{ Kelompok } & \multirow{2}{*}{ Rata-rata } & \multicolumn{7}{|c|}{ t-test for Equality of means } \\
\cline { 5 - 8 } & & df & T tab & T hit & P & Sig 5\% & Selisih \\
\hline Pre-test & 56,5000 & \multirow{2}{*}{11} & 2,201 & 8,660 & 0,000 & 0,05 & 2.5 \\
\hline Post-test & 59,0000 & & & &
\end{tabular}

\section{Perbandingan Pretest dan Posttest Kemampuan Vertical Jump dengan latihan Plyometric Standing Jump}

Dari hasil uji-t dapat dilihat bahwa t hitung $(3,522)>\mathrm{t}$ tabel $(2,201)$, dan nilai $p(0,005)$ $<$ dari $(0,05)$, maka hasil tersebut menunjukkan bahwa terdapat perbedaan yang signifikan, Dari data pre-test memiliki rerata 48.9, selanjutnya pada posttest rerata mencapai 53.1 . besarnya perubahan tersebut dapat dilihat dari perbedaan rata-rata yaitu sebesar $4.25 \mathrm{~cm}$. 
MEDIKORA, Vol. XVIII No. 2 Oktober 2019 - 69

Bayu Adhitya Bagaskara, Suharjana

Tabel 9. Hasil pre-test dan post-test vertical jump kelompok latiahan standing jump

\begin{tabular}{|c|c|c|c|c|c|c|c|}
\hline \multirow{2}{*}{ kelompok } & \multirow{2}{*}{ Rata-rata } & \multicolumn{7}{|c|}{ t-test for Equality of means } \\
\cline { 5 - 8 } & & Df & t tab & $\mathbf{t}$ hit & $\boldsymbol{P}$ & Sig 5 \% & Selisih \\
\hline Pre-test & 48,9167 & \multirow{2}{*}{11} & 2,201 & 3,522 & 0,005 & 0,05 & 4.25 \\
\hline Post-test & 53,1667 & & &
\end{tabular}

\section{Perbandingan Postest Kemampuan Vertical Jump dengan Latihan Plyometric Box Jump dan Plyometric Standing Jump}

Dari hasil uji-t dapat dilihat bahwa thitung $(2,133)>\mathrm{t}$ tabel $(1,720)$, dan nilai $p(0,269)$ $<$ dari $(0,05)$, maka hasil tersebut menunjukkan bahwa terdapat perbedaan antara post-test kelompok plymetrik box jump dengan post-test kelompok plyometric standing jump atlet bola voli putra Ganevo usia 14-17 tahun dibanding dengan latihan plyometric box jump. Berdasarkan hasil analisis diperoleh nilai rerata selisih post-test kelompok box jump sebesar $2.5 \mathrm{~cm}$, nilai rerata post-test kelompok standing jump sebesar $4.25 \mathrm{~cm}$, dilihat dari selisih nilai post-test sebesar $1.75 \mathrm{~cm}$.

Berdasarkan hasil analisis diperoleh nilai rerata selisih post-test kelompok box jump sebesar $2.5 \mathrm{~cm}$, nilai rerata post-test kelompok standing jump sebesar $4.25 \mathrm{~cm}$, dilihat dari selisih nilai post-test sebesar $1.75 \mathrm{~cm}$.

Tabel 10. Hasil Uji gain score

\begin{tabular}{|c|c|c|c|c|c|c|c|}
\hline \multirow{2}{*}{ kelompok } & \multirow{2}{*}{ Rata-rata } & \multicolumn{5}{|c|}{ t-test for Equality of means } \\
\cline { 3 - 8 } & Df & $\mathbf{t}$ tab & $\mathbf{t}$ hit & $\boldsymbol{P}$ & Sig 5 \% & Selisih \\
\hline $\begin{array}{c}\text { Post-test box } \\
\text { jump }\end{array}$ & 2.5 & \multirow{2}{*}{22} & 1,720 & 2,133 & 0,269 & 0,05 & 1.75 \\
\hline $\begin{array}{c}\text { Post-test } \\
\text { standing jump }\end{array}$ & 4.25 & & & & & \\
\hline
\end{tabular}

\section{SIMPULAN}

Terdapat pengaruh signifikan latihan plyometric box jump dan standing jump terhadap vertical jump atlet bola voli putra Ganevo usia 14-17 tahun dengan kenaikan presentase sebesar $4,44 \%$ atau $2,5 \mathrm{~cm}$. Latihan plyometric standing jump lebih baik untuk meningkatkan vertical jump daripada box jump pada atlet bola voli putra ganevo usia 14-17 tahun.

\section{DAFTAR PUSTAKA}

Ahmadi, N. (2007). Panduan olahraga bola voli. Solo: Era Pustaka Utama.

Indrayana, B. (2018). Perbedaan pengaruh latihan knee tuck jump dengan latihan double leg bound terhadap peningkatan power otot tungkai dan kemampuan smash pada ekstrakurikuler bola voli putra smkn 1 kota jambi. JORPRES (Jurnal Olahraga Prestasi), 14(1), 1-23.

Reza, (2017). Pengaruh lathan plyometrics dan kekuatan terhadap kemampuan power otot tungkai dan kelincahan peserta ekstrakurikuler bola voli putra.Tessis,Program Pasca Sarjana UNY: Ilmu Keolahragaan

Suharjana. (2013). Kebugaran jasmani. Yogyakarta: Jogja Global Media.

Sugiyono. (2014)."Metode Penelitian Kuantitatif, Kualitatif dan R\&D." Bandung. Penerbit Alfabeta. 